\title{
Blood lactate concentration as prognostic marker in critically ill children
}

\author{
Adriana Koliski, ${ }^{1}$ Izrail Cat, $^{2}$ Dinarte ${ }^{2}$. Giraldi, ${ }^{2}$ Mônica L. Cat ${ }^{3}$
}

\begin{abstract}
Objective: To assess the use of lactate as a marker of tissue hypoperfusion and as a prognostic index in critically ill patients.

Methods: Prospective, longitudinal, observational study of 75 patients admitted to the pediatric ICU of Hospital de Clínicas of Universidade Federal do Paraná, between November 1998 and May 1999. According to the lactate level on admission, patients were divided into group A (lactate $\geq 18 \mathrm{mg} / \mathrm{dl}$ ) and group B (lactate $<18 \mathrm{mg} / \mathrm{dl}$ ). In terms of outcome, patients were classified into survivors and nonsurvivors. In group $A$, the clinical evaluation and the collection of arterial blood samples were performed on admission, at 6, 12, 24, 48 hours, and every 24 hours after that. In group $B$, they were carried out in the same way, but interrupted 48 hours after admission.

Results: Groups A and B consisted of 50 and 25 patients, respectively. Group A presented more clinical signs of hypoperfusion (24/50). There was a statistically significant difference regarding the mean lactate levels on admission between those patients who died within 24 hours of admission $(95 \mathrm{mg} / \mathrm{dl})$ and those who died 24 hours after admission $(28 \mathrm{mg} / \mathrm{dl})$. The lactate level at 24 hours of admission revealed better sensitivity (55.6\%) and specificity (97.2\%) as a predictor of death.

Conclusions: Most patients with lactate levels $\geq 18 \mathrm{mg} / \mathrm{dl}$ showed clinical signs of hypoperfusion on admission. The normalization or reduction of lactate levels at and after 24 hours of admission was significantly related with higher chances
\end{abstract} of survival.

J Pediatr (Rio J). 2005;81(4):287-92: Blood lactate, lactic acidosis, hyperlactatemia, prognostic index, PICU mortality.

\section{Introduction}

Clinical findings and lab test results on admission to the intensive care unit (ICU) reflect the most recent pathophysiological findings. The events in the hours that follow admission are often a development of those events. Based on this information, the changes in these parameters on admission as well as in the outcome of ICU patients have been used to establish the risk of death, both in adults and children, and blood lactate levels are one of the most commonly used methods. ${ }^{1}$

1. MSc. Pediatrician, Intensive Care Unit, Hospital de Clínicas, Universidade Federal do Paraná (UFPR), Curitiba, PR, Brazil.

2. PhD. Professor, Department of Pediatrics, UFPR, Curitiba, PR, Brazil.

3. Assistant professor, Department of Pediatrics, UFPR. Coordinator of the Computing and Statistics Unit, Department of Pediatrics, UFPR, Curitiba, PR, Brazil.

Manuscript received Jul 01 2004, accepted for publication Mar 162005.

Suggested citation: Koliski A, Cat I, Giraldi DJ, Cat ML. Blood lactate concentration as prognostic marker in critically ill children. J Pediatr (Rio J). 2005;81:287-92.
Blood lactate levels are used in several situations, such as marker for tissue hypoperfusion in shock patients, indicator of adequate post-shock resuscitation, prognostic index after resuscitation, prognostic factor in case of severe diseases, ${ }^{2}$ and as etiologic diagnosis. ${ }^{3,4}$

Most cases of hyperlactatemia in critically ill patients are due to inappropriate tissue oxygenation. This condition may result from respiratory disorders with poor blood oxygenation or from circulatory disorders that cause tissue hypoperfusion. As patients with tissue hypoperfusion do not always show clinical signs, hyperlactatemia may be the only marker for this disorder. 5,6

Lactic acidosis is defined as a metabolic acidosis in which arterial blood lactate levels are equal to or greater than $45 \mathrm{mg} / \mathrm{dl}(5 \mathrm{mmol} / \mathrm{l})$ and the arterial $\mathrm{pH}$ is less than 7.35. ${ }^{7}$ Critically ill patients may have normal lactate levels up to 18 $\mathrm{mg} / \mathrm{dl}{ }^{6}$ although arterial blood reference values can reach as much as $10 \mathrm{mg} / \mathrm{dl}$. Values between 18 and $45 \mathrm{mg} / \mathrm{dl}$ are described as being in the "gray zone," whose importance has not been established yet. In critically ill patients whose 
arterial blood lactate levels amount to 18 and $45 \mathrm{mg} / \mathrm{dl}$, the main goal is to determine whether there is hypoperfusion, because if it is not detected, there may be potentially deleterious consequences. 6

The present study aims to verify the use of hyperlactatemia as a marker for tissue hypoperfusion (anaerobic metabolism) and as a prognostic index in critically ill patients.

\section{Patients and methods}

This study was carried out at the pediatric intensive care unit (PICU), Department of Pediatrics of Hospital de Clínicas (HC) of Universidade Federal do Paraná (UFPR), between November 1998 and May 1999. This was a prospective, longitudinal and observational study. The protocol was approved by the Human Research Ethics Committee of Hospital de Clínicas (UFPR).

During the study period, 182 children were admitted to the PICU. A total of 75 patients participated in the study, regardless of their underlying disease. Children younger than 28 days were not included, and neither were those patients whose admission had occurred at a time in which clinical and laboratory data could not be collected by the observer (always the same observer).

The criteria for admission to the PICU, diagnostic and treatment procedures were those of protocols already in use by the PICU. The nutritional assessment of patients was carried out according to the National Center of Health Statistics (NCHS) standards. The clinical signs of hypoperfusion were adopted from the American Academy of Pediatrics, $1998 .^{8}$

Arterial blood samples were collected at every clinical assessment point and then processed in a $\mathrm{pH}$, gas and electrolyte analyzer (model ABL 635, from Radiometer).

Although reference arterial blood values are considered to be $10 \mathrm{mg} / \mathrm{dl}$, the following values were defined to be normal for critically ill patients in this study: blood lactate levels of up to $18 \mathrm{mg} / \mathrm{dl}$; hyperlactatemia between 18 and $45 \mathrm{mg} / \mathrm{dl}$ without metabolic acidosis and lactic acidosis, with levels greater than $45 \mathrm{mg} / \mathrm{dl}$ and $\mathrm{pH}$ below 7.35.6

According to the lactate level observed on admission, the patients were subdivided into two groups: Group A, patients admitted to the PICU with lactate levels equal to or greater than $18 \mathrm{mg} / \mathrm{dl}$, and Group B, patients with lactate levels less than $18 \mathrm{mg} / \mathrm{dl}$.

In group $A$, clinical and laboratory assessments were made on admission, at $6,12,24,36$, and 48 hours and every 24 hours thereafter. Assessment was suspended upon normalization of lactate levels, discharge from the PICU, or death. In group B patients, assessments were performed always at the same time, and were suspended at 48 hours or less in case of discharge or death.

With regard to diagnosis, the patients were classified as receiving cardiac postoperative care, having infection (subdivided into sepsis, meningitis, bronchopneumonia, gastroenterocolitis and other infections), diabetes mellitus, other postoperative disorders, and miscellaneous. As to the outcome, patients were divided into survivors and nonsurvivors.

\section{Statistics}

Sample size was estimated by considering a maximum type I error probability of 5\% (alpha) and a type II error of $20 \%$ with an estimated power of $80 \%$, depending on the analysis performed.

The continuous variables with normal distribution are expressed as means \pm 2 SD and were compared using Student's t test, whereas continuous variables with an asymmetric distribution were expressed as median and the respective range interval (minimum and maximum) and were compared using nonparametric Mann-Whitney test, for independent samples. In the case of categorical variables, Pearson's chi-square test, Yates' correction in $2 \times 2$ contingency tables and Fisher's exact test were used to analyze differences in proportions. A logistic regression model was used to assess the possible relationship between continuous variables and the probability of an event. The significance level was established at $p<0.05$ for all tests. A ROC (Receiver Operating Characteristic) curve with a $95 \%$ CI was used to check the ability of a variable to predict outcome (survival or death). 9

For most patients, normalization of lactate levels occurred within the first 48 hours or, in some other cases, discharge or death occurred. For this reason, statistical analysis was only made until that period.

\section{Results}

With regard to lactate levels on admission, 50 patients were included in Group A and 25 patients in Group B. Three patients showed normal lactate levels on admission, but those levels increased to over $18 \mathrm{mg} / \mathrm{dl}$ before the sixth hour and, for that reason, the patients were included in Group $A$. Of the 47 patients who had lactate levels $\geq 18 \mathrm{mg} / \mathrm{dl}$ on admission, 31 showed levels between 18 and $45 \mathrm{mg} / \mathrm{dl}$ and 16 had levels greater than $45 \mathrm{mg} / \mathrm{dl}$. Of these, 14 cases had concomitant metabolic acidosis.

The characteristics of the study groups are shown in Table 1.

Table 2 shows the distribution of 75 patients according to diagnosis and blood lactate levels on admission to the PICU.

On admission to the ICU, Group A patients had a higher frequency of clinical signs of hypoperfusion (Group A: 24/50; Group B: 3/25; $p=0.0001)$. The signs of hypoperfusion observed on physical examination at the moment of admission to the ICU are shown in Table 3.

At 6 hours, signs of hypoperfusion were also more frequent in Group A (Group A - 12/47; Group B - 1/25; $p=0.02$ ), in addition to hypophonesis of the cardiac sounds (Group A - 29/47; Group B - 8/25; p = 0.02). At 12, 24, 36 and 48 hours, no statistically significant differences as to clinical signs were observed between the groups. 
As to lab tests on admission, the median blood lactate level in Group A was $35.5 \mathrm{mg} / \mathrm{dl}$ (Min-Max: 6-191 mg/dl) and $10 \mathrm{mg} / \mathrm{dl}$ (Min-Max: 4-17 mg/dl) in Group B. In addition to lactate levels, statistically significant differences were found between median glucose levels (Group A - 181.5 mg/dl, Min-Max: 13-992 mg/dl; Group B - $128 \mathrm{mg} / \mathrm{dl}$, Min-Max: 72-401 mg/dl; $p=0.01$ ), with no differences regarding other lab tests performed on admission or during treatment. The median lactate levels at the different assessment times are shown in Table 4.

As far as diagnosis is concerned, the 31 cases of infection included: seven $(22.5 \%)$ cases of meningitis, eight $(25.8 \%)$ cases of sepsis, nine $(29 \%)$ cases of bronchopneumonia, two $(6.4 \%)$ cases of gastroenteritis and five $(16 \%)$ cases of other infections.

Of the patients hospitalized for cardiac postoperative care, all of the 10 patients included in Group A were submitted to extracorporeal circulation. This procedure was not performed in the four patients of Group B.

With regard to the use of mechanical ventilation, Group A patients were more frequently submitted to mechanical ventilation than were patients in Group B (Group A - 32/50; Group B - 09/25; $p=0.02$ ), and also needed more inspired oxygen fraction (Group A - 75.8 $\$ 32.1 \%$; Group B $53.4 \pm 38.2 \% ; p=0.01)$.

Eighteen patients died ( 15 in Group A and three in Group B), seven $(38.9 \%)$ of whom died within the first 24 hours. As to the median blood lactate level on admission, there was a statistically significant difference between the patients who died within the first 24 hours $(95 \mathrm{mg} / \mathrm{dl}$, Min-Max: $19-191 \mathrm{mg} / \mathrm{dl}$ ) and those who died after 24 hours from the time of the admission ( $28 \mathrm{mg} / \mathrm{dl}$, Min-Max: $5-74 \mathrm{mg} / \mathrm{dl}$ ).

Blood lactate levels at 0, 12, 24, 36 and 48 hours of admission were analyzed using logistic regression in order to verify the use of blood lactate as a prognostic marker for death.

The probability curve calculated with blood lactate levels on admission showed that extremely high levels of lactate are necessary to determine a risk of death greater than $50 \%$ $(p=0.03)$. By excluding the cases with blood lactate levels $>80 \mathrm{mg} / \mathrm{dl}$ (five cases), we noted that blood lactate levels of up to $30 \mathrm{mg} / \mathrm{dl}$ presented no significant difference as to

Table 1 - General characteristics of Groups A and B

\begin{tabular}{|c|c|c|c|c|}
\hline & $\mathbf{n}$ & Group A & Group B & $\mathbf{p}$ \\
\hline Number of patients & 75 & 50 & 25 & \\
\hline Age (months) & 75 & $22.5(1-168)$ & $47(3-160)$ & 0.37 \\
\hline Weight (kg) & 75 & $11.3(3-58)$ & $13.8(3-56)$ & 0.41 \\
\hline Height $(\mathrm{cm})$ & 75 & $91.5( \pm 34.1)$ & $100.1( \pm 34.5)$ & 0.31 \\
\hline Gender & 75 & $34 \mathrm{M} / 16 \mathrm{~F}$ & $13 \mathrm{M} / 12 \mathrm{~F}$ & 0.21 \\
\hline \multirow[t]{3}{*}{ Nutrition } & 75 & 35 well-nourished & 16 well-nourished & \\
\hline & & 13 undernourished & 5 undernourished & \\
\hline & & 2 overweight & 4 overweight & 0.18 \\
\hline Length of hospital stay $(h)$ & 75 & $2(3-504.0)$ & $72(12-384)$ & 0.54 \\
\hline Outcome & 75 & $15 / 50(30 \%)$ death & $3 / 25(12 \%)$ death & 0.14 \\
\hline
\end{tabular}

$\mathrm{n}=$ sample size $; \mathrm{M}=$ male $; \mathrm{F}=$ female $\mathrm{h}=$ hours.

Table 2 - Number of patients in Groups A and B according to diagnosis

\begin{tabular}{lccc}
\hline Diagnosis & n & Group A & Group B \\
\hline Infections & 31 & 22 & 9 \\
Cardiac surgery postoperative care & 14 & 10 & 4 \\
Other surgeries postoperative care & 13 & 8 & 5 \\
Diabetes mellitus & 5 & 2 & 3 \\
Miscellaneous & 12 & 8 & 4 \\
\hline
\end{tabular}

$\mathrm{n}$ = sample size.
Table 3 - Clinical signs of hypoperfusion at admission to the pediatric intensive care unit

\begin{tabular}{|c|c|c|c|}
\hline Sign & Group A & Group B & $\mathbf{p}$ \\
\hline $\begin{array}{l}\text { Diastolic blood pressure } \\
(\mathrm{mmHg})\end{array}$ & $\begin{array}{c}54.3 \\
( \pm 20.1)\end{array}$ & $\begin{array}{c}65.6 \\
( \pm 13.0)\end{array}$ & 0.02 \\
\hline Decreased heart sounds & $37 / 50$ & $12 / 25$ & 0.03 \\
\hline Cyanosis & $11 / 50$ & $0 / 25$ & 0.01 \\
\hline $\begin{array}{l}\text { Pallor (skin and } \\
\text { mucous membrane) }\end{array}$ & $30 / 50$ & $8 / 25$ & 0.02 \\
\hline
\end{tabular}


Table 4 - Median lactate levels $(\mathrm{mg} / \mathrm{dl})$ in Groups A and B at different assessment moments

\begin{tabular}{lccc}
\hline & Group A & Group B & p \\
\hline oh & $35.5(6-191)$ & $10.0(4-17)$ & 0.00000 \\
$6 \mathrm{~h}$ & $22.0(6-121)$ & $9.0(5-18)$ & 0.00000 \\
$12 \mathrm{~h}$ & $18.5(6-63)$ & $9.0(5-19)$ & 0.00000 \\
$24 \mathrm{~h}$ & $21.5(5-53)$ & $10.0(3-27)$ & 0.00001 \\
$36 \mathrm{~h}$ & $23.0(8-47)$ & $12.0(4-22)$ & 0.00035 \\
$48 \mathrm{~h}$ & $19.0(5-41)$ & $6.0(6-22)$ & 0.00331 \\
\hline
\end{tabular}

the risk of death $(p=0.07)$. We observed, especially in assessments after 24 hours of admission, that normalization of blood lactate levels $(<18 \mathrm{mg} / \mathrm{dl}$ ) significantly reduces the risk of death $(p=0.0009)$.

On admission, lactate levels of $25 \mathrm{mg} / \mathrm{dl}$ produced the best sensitivity and specificity (70.6 and $63.2 \%$, respectively). The area under the ROC curve corresponded to 0.684 ( $\mathrm{CI}=0.566$ to 0.787 ) (Table 5). At 12 hours, sensitivity of $63.6 \%$ and specificity of $60.7 \%$ were obtained for blood lactate levels greater than $12 \mathrm{mg} / \mathrm{dl}$. The area under the ROC curve corresponded to 0.623 ( $\mathrm{CI}=0.497$ to 0.739 ). The best sensitivity and specificity ( 55.6 and $97.2 \%$, respectively) for a lactate level of $27 \mathrm{mg} / \mathrm{dl}$ were obtained at 24 hours. The area under the ROC curve corresponded to 0.809 ( CI $=0.664$ to 0.910$)$, (Figure 1 ).

Thus, the ROC curve allows us to conclude that lactate levels on admission and after 12 hours of treatment were not efficient in predicting the risk of death among the patients. Only after 24 hours of treatment the lactate level can predict survival and risk of death. This was the moment with the best sensitivity and specificity (Figure 1).

Table 5 - Sensitivity and specificity values according to lactate levels (ROC curve)

\begin{tabular}{lcccc}
\hline & $\begin{array}{c}\text { Lactate } \\
\text { level }\end{array}$ & Sensitivity & Specificity & $\begin{array}{c}\text { Area of the } \\
\text { ROC curve }\end{array}$ \\
\hline $0 \mathrm{~h}$ & $25 \mathrm{mg} / \mathrm{dl}$ & $70.6 \%$ & $63.2 \%$ & 0.684 \\
$12 \mathrm{~h}$ & $12 \mathrm{mg} / \mathrm{dl}$ & $63.6 \%$ & $60.7 \%$ & 0.623 \\
$24 \mathrm{~h}$ & $27 \mathrm{mg} / \mathrm{dl}$ & $55.6 \%$ & $97.2 \%$ & 0.809 \\
\hline
\end{tabular}

\section{Discussion}

Measurement of blood lactate in critically ill patients has shown prognostic value in several situations (e.g.: trauma, shock, and other severe diseases in adults and children, and also in preterm newborns). ${ }^{10}$ Patients admitted to ICU often have higher blood lactate levels than those admitted to other units. This is due to the fact that these patients frequently present perfusion disorders, with consequent tissue hypoxia. ${ }^{11}$

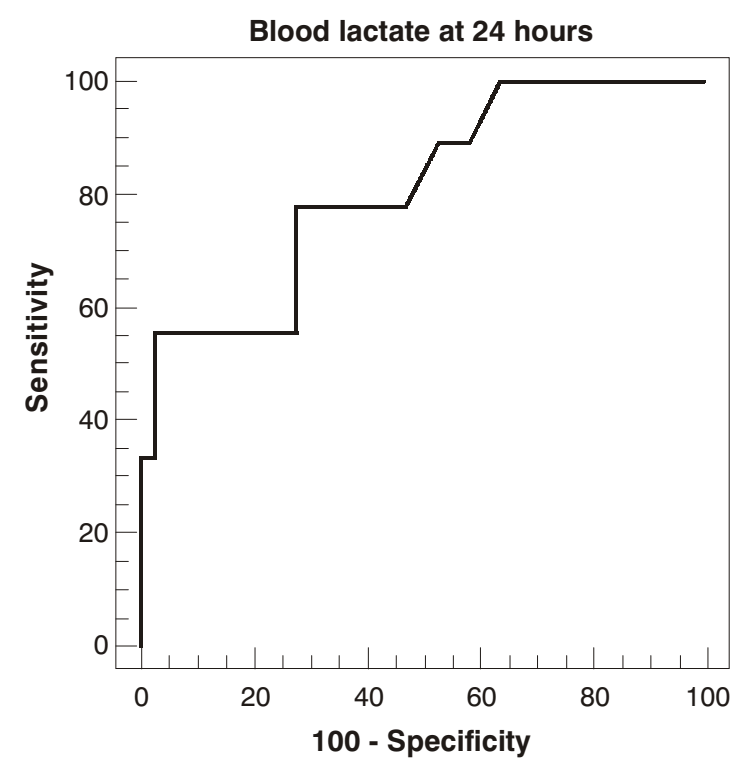

Figure 1 - ROC curve - blood lactate 24 hours after admission to the intensive care unit

Most patients with lactate levels greater than $50 \mathrm{mg} / \mathrm{dl}$ on admission had lactic acidosis. The occurrence of lactic acidosis in hypoperfusion states is a common finding ${ }^{12}$ and this association probably does not depend directly on elevated lactate levels, but rather on the $\mathrm{H}^{+}$resulting from the hydrolysis of ATP stores as a consequence of tissue hypoxia. ${ }^{5}$ On the other hand, there will also be an increase in $\mathrm{H}^{+}$due to the reduced use of lactate in gluconeogenesis or in the Krebs cycle. ${ }^{13}$

In cardiogenic, hypovolemic or septic shock with tissue hypoxia there is usually an imbalance between the increased need of energy and ATP synthesis. This causes an increase in the glycolisis, resulting in a larger lactate production. In sepsis, in addition to the inhibition of the metabolic pathways that carry $\mathrm{H}^{+}$from the cytoplasm to the mitochondria, there is an increase in branched-chain amino acid oxidation and an increase in glycolytic flow due to the increased phosphofructokinase activity. ${ }^{14}$ These changes take place in most organs, apparently under adequate conditions of oxygen transport and supply to the tissues. ${ }^{4}$

In our patient population, most cases of sepsis showed signs of hypoperfusion at every assessment. However, in cases of sepsis, there may be inadequate tissue perfusion in the absence of clinical signs (occult hypoperfusion). Its mechanism has not been clearly described, but it may involve a combination of factors such as a change in the distribution of blood flow by vasodilation, or an increase in the diffusion distance between the capillary and the cell as a result of interstitial edema, associated with capillary injury. ${ }^{15}$

Of the eight sepsis cases, only one did not have high levels of lactate. This fact has already been described and may be explained by the development of a compensatory 
hemodynamic response. ${ }^{16}$ In the cases in which such response cannot be detected, lactate level remains elevated or increases during hospitalization leading to a $100 \%$ mortality rate. 15

These findings led intensivists to check whether lactate concentration, besides being clinically useful as an indicator of circulatory involvement and of the oxygenation state, could also be used as prognostic marker for the risk of death among critically ill patients. $5,16,17$

Hyperlactatemia has been detected in critically ill patients and several clinical studies have shown an association between its levels and the type of outcome, with higher levels in those patients who will eventually die. ${ }^{18}$ In our patient population, the mean blood lactate level of patients who died was higher than in those who survived.

An increase in mortality has been observed among patients with lactate levels greater than $22 \mathrm{mg} / \mathrm{dl} .{ }^{19}$ Vincent et al. describe that shock patients with the best prognosis were those in whom lactate levels had considerably decreased within one hour after resuscitation. ${ }^{20}$ Husain et al. demonstrated that lactate levels in surgical patients on admission and after 24 hours of hospitalization were correlated with mortality. ${ }^{21}$ Broder \& Weil noted that only $11 \%$ of those with serum lactate level greater than $36 \mathrm{mg} /$ dl survived. ${ }^{5}$ Moreover, Smith et al. suggest that hyperlactatemia can identify patients at risk of death and can also be used as an indicator of ICU admission. ${ }^{22}$

This association was also observed in septic shock patients, where the length of hyperlactatemia, just as initial lactate levels, had a prognostic value, being the best indicator of survival and of organ dysfunction. 23,24 Marecaux et al. showed that, when correlated with other markers, lactate has a better prognostic value than the tumor necrosis factor and IL-6. ${ }^{25}$ Smith et al. concluded that lactate can be used for the prognosis of outcome in (adult) ICU patients. 22

Besides these studies with adults, observations in pediatric patients for the establishment of laboratory parameters as predictors of death have presented controversial results. When compared with other parameters, blood lactate levels were not correlated with mortality. ${ }^{26}$ Hatherill et al. found that initial lactate concentration in children submitted to cardiac surgery cannot predict death. 27

On the other hand, Sanz et al. found out that PIM (Pediatric Index Mortality) and lactate have a prognostic value in critically ill children. ${ }^{1}$ Siegel et al. observed that, in children admitted to the ICU after a cardiac surgery, high levels of lactate had a positive predictive value of $100 \%$ and a negative predictive value of $97 \%$ for death. ${ }^{28}$ By using univariate logistic regression, Duke et al. found that lactate allowed distinguishing survivors from nonsurvivors among children with sepsis at 12 and 24 hours of admission. ${ }^{29}$ Hatherill et al. suggest that hyperlactatemia can indicate death on admission and if it persists after 24 hours of treatment. ${ }^{30}$ For children in cardiac postoperative care, duration of extracorporeal circulation and lactate level, measured in the immediate postoperative period, were the best predictors of the risk of clinical and surgical complications in the first 48 postoperative hours and also the best predictor of death. 29

In our cases, the probability curve on admission to the ICU showed that a risk of death greater than $50 \%$ only occurs with extremely high lactate levels. Up to $30 \mathrm{mg} / \mathrm{dl}$ there is no significant difference as to the risk of death. Lactate measurements at zero and at 12 hours did not allow identifying the group at risk of death. This was observed in the logistic regression analysis and in the ROC curve. However, in the outcome assessment, the ROC curve revealed that there is better sensitivity and specificity for survival when lactate levels decrease or normalize within 24 hours.

In conclusion, this study demonstrated that most patients who died had higher blood lactate levels than those who survived and that, for the prediction of death, its serial monitoring is better than its isolated measurement. Blood lactate levels on admission did not have sensitivity or specificity as a predictor of death. Nevertheless, the reduction or normalization of lactate levels after 24 hours of admission was significantly related to higher chances of survival. As a predictor of death, blood lactate level at 24 hours of ICU admission presented the best sensitivity and specificity. The limitations of our study are the number of patients analyzed and the various diagnoses, making the sample heterogeneous. Thus, subdivision into groups leads to very low sample values. Therefore, further studies are necessary to confirm the predictive value of lactate in pediatric patients admitted to the ICU. Until new biochemical markers are discovered, we believe that blood lactate is useful as a prognostic marker.

\section{References}

1. Sanz CG, Lucas MR, Cid JL, Escribano DV, Cantarero GG. Valor pronóstico de la puntuación PIM (índice pediátrico de mortalidad) y del ácido láctico en niños críticamente enfermos. An Esp Pediatr. 2002;57:394-400.

2. Gotay-Cruz F, Aviles-Rivera DH, Fernandez-Sein A. Lactic acid levels as prognostic measure in acutely ill patients. Puerto Rico Health Sci J. 1991;10:9-13.

3. Mizock BA. Significance of hyperlactatemia without acidosis during hypermetabolic stress. Crit Care Med. 1997;25:1780-1.

4. Kliegel A, Losert H, Sterz F, Holzer M, Zeiner A, Havel C, et al. Serial lactate for prediction of outcome after cardiac arrest. Medicine (Baltimore). 2004;83:274-9.

5. Meregalli A, Oliveira RP, Friedman G. Occult hypoperfusion is associated with increase mortality in hemodynamically stable, high-risk, surgical patients. Critical Care. 2004;8:R60-64.

6. Mizock BA. Lactic acidosis. Dis Month.1989;35:2451-300.

7. Stacpoole PW. Lactic acidosis. Endocrinol Metabol Clin North Am. 1993;22:221-45.

8. American Academy of Pediatrics. The Pediatric Emergency Medicine Course. 3rd ed. Elk Grove Village (IL): AAP; 1998.

9. Metz C. Basic principles of ROC analysis. Sem Nucl Med. 1978;8: 283-98.

10. Deshpand S, Platt M. Association between blood lactate and acid-base status and mortality in ventilated babies. Arch Dis Child. 1997;76:F15-F20.

11. Mizock BA, Falk JL. Lactic acidosis in critical illness. Crit Care Med. 1992;20:80-93.

12. Hatherill M, Waggie $Z$, Purves $L$, Reynolds $L$, Argent A. Mortality and the nature of metabolic acidosis in children with shock. Int Care Med. 2003;29:286-91. 
13. Zilva JF. The origin of the acidosis in hyperlactataemia. Ann Clin Biochem. 1978;15:40-3.

14. Cohen $\mathrm{R}$, Woods $\mathrm{H}$. Clinical and biochemical aspects of lactic acidosis. London: William Cloves \& Sons Ltd; 1976.

15. Nimmo GR, Mackenzie SJ, Walker SW, Catnach J, Nicol M, Armstrong IR, et al. The relationship of blood lactate concentrations, oxygen delivery and oxygen consumption in septic shock and adult respiratory distress syndrome. Anaesthesia. 1992;47:1023-8.

16. Levraut J, Ichai C, Petit I, Ciebiera JP, Perus O, Grimaud D. Low exogenous lactate clearance as an early predictor of mortality in normolactatemic critically ill septic patients. Crit Care Med. 2003;31:705-10.

17. Hatherill M, McIntyre AG, Wattie M, Murdoch IA. Early hyperlactatemia in critically ill children. Int Care Med. $2000 ; 26$ : 314-8.

18. Nguyen HB, Rivers EP, Knoblich BP, Jacobsen G, Muzzin A, Ressler JA, et al. Early lactate clearance is associated with improved outcome in severe sepsis and septic shock. Crit Care Med. 2004;32:1637-42.

19. Maillet JM, Lê Besnerais $P$, Cantoni $M$, Nataf $P$, Ruffenach $A$, Lessana $A$, et al. Frequency, risk factors, and outcome of hyperlactatemia after cardiac surgery. Chest. 2003;123:1361-6.

20. Vincent JL, Dufaye P, Berre J, Leeman M, Degaute JP, Kahn RJ. Serial lactate determinations during circulatory shock. Crit Care Med. $1983 ; 11: 449-51$.

21. Husain FA, Martin MJ, Mullenix PS, Steele SR, Elliott DC. Serum lactate and base deficit as predictors of mortality and morbidity. Am J Surg. 2003;185:485-91.

22. Smith I, Kumar P, Molloy S, Rhodes A, Newman PJ, Grounds RM, et al. Base excess and lactate as prognostic indicators for patients admitted to intensive care. Intensive Care Med. 2001;27:74-83.

23. Bernardin G, Pradier C, Tiger, F, Deloffre, P, Mattei, M. Blood pressure and arterial lactate level are early indicators of shortterm survival in human septic shock. Intensive Care Med. $1996: 22: 17-25$.
24. Levy B, Sadoune LO, Gelot AM, Bollaert PR, Nabet P, Larcan A. Evolution of lactate/pyruvate and arterial ketone body ratios in the early course of catecholamine-treated septic shock. Crit Care Med. 2000;28:114-9.

25. Marecaux G, Pinsky MR, Dupont E, Kahn RJ, Vincent JL. Blood lactate levels are better prognostic indicators than TNF and IL - 6 levels in patient with septic shock. Intensive Care Med. $1996 ; 22: 404-8$.

26. Balasubramanyan N, Havens PL, Hoffman GM. Unmeasured anions identified by the Fencl-Stewart method predict mortality better than base excess, anion gap, and lactate in patients in the pediatric intensive unit. Crit Care Med. 1999;27:1577-81.

27. Hatherill M, Sajjanhar T, Tibby SM, Champion MP, Anderson D, Marsh MJ, et al. Serum lactate as a predictor of mortality after paediatric cardiac surgery. Arch Dis Child. 1997;77:235-8.

28. Siegel LB, Dalton HJ, Hertzog JH, Hopkins RA, Hannan RL, Hauser GL. Initial postoperative serum lactate levels predict survival in children after open heart surgery. Intensive Care Med. 1996;22:1418-23.

29. Duke T, Butt W, South M, Karl TR. Early markers of major adverse events in children after cardiac operations. J Thorac Cardiovasc Surg. 1997;114:1042-52.

30. Hatherill M, McIntyre AG, Wattie M, Murdoch IA. Neonatal and pediatric intensive care: early hyperlactatemia in critically ill children. Intensive Care Med. 2000;26:314-18.

\section{Correspondence:}

Adriana Koliski

Av. Paraná, 45/81, Cabral

CEP 80030-135 - Curitiba, PR, Brazil

Tel.: +55 (41) 254.5022

E-mail: akoliski@yahoo.com.br 